\title{
“UM MOÇO MUITO BRANCO”: A CONSTRUÇÃO DO INSÓLITO NA OBRA DE JOÃO GUIMARÃES ROSA
}

\author{
"UM MOÇO MUITO BRANCO": THE CONSTRUCTION OF THE UNUSUAL IN THE \\ WORKS OF JOÃO GUIMARÃES ROSA
}

\author{
Arnaldo Nogari Júnior (UENP-Jacarezinho) $)^{1}$ \\ Nerynei Meira Carneio Bellini (UENP-Jacarezinho) ${ }^{2}$
}

\begin{abstract}
RESUMO: Como se sabe, a literatura é capaz de levar o ser humano a vivenciar emoções intensas e distintas. Todorov (1975) destaca a literatura fantástica e, em seus estudos, mostra que essa se traduz como vacilação experimentada por um indivíduo que não reconhece mais as regras do mundo real, diante de um fenômeno visivelmente fantástico, o que certamente provoca anseio no leitor. Desse modo, com base em nossas experiências, constata-se que diversas obras literárias aludem ao fantástico, o qual pode variar entre o estranho e o maravilhoso. Portanto, as narrativas fantásticas não devem ser meramente classificadas como tal, mas é indispensável considerar suas mutações, estilos e intenções de produção. Diante disso, o presente artigo propõe a análise do conto "Um moço muito branco", de João Guimarães Rosa (1972), com o intuito de averiguar aspectos insólitos presentes nessa narrativa e como as mesmas são incorporadas textualmente.
\end{abstract}

PALAVRAS-CHAVE: Literatura Fantástica. Guimarães Rosa. "Um moço muito branco”.

ABSTRACT: As we all know, the literature is able to take the human being to experience intense and distinct emotions. Todorov (1975) highlights fantasy literature, and, in his studies, shows that this kind of literature translates the hesitation experienced by an individual who does not recognize real-world rules when in face of a visibly fantastic phenomenon, which certainly causes anxiety in the reader. Thus, based on our experiences, we have noted that several literary works allude to the fantastic, which can vary between the fantastic uncanny and the fantastic marvelous. Therefore, fantastic narratives should not be merely labelled as such; it is essential to consider its mutations, styles and production intentions. All this considered, this article proposes an analysis of the short story "Um moço muito branco" by João Guimarães Rosa (1972), in order to investigate unusual aspects present in this narrative and the ways in which they are incorporated to the text.

KEYWORDS: Fantasy Literature. Guimarães Rosa. Um moço muito branco.

\footnotetext{
${ }^{1}$ Possui graduação em Letras (Português/ Inglês) e especialização em Estudos Linguísticos e Literários, pela Universidade Estadual do Norte do Paraná (UENP), campus de Jacarezinho. É ainda especialista em Educação Especial e Inclusiva pela Faculdade de Tecnologia Paulista e especialista em Literatura Brasileira pela Faculdade São Braz. Desenvolve pesquisas na área de literatura do insólito. E-mail: arnaldo_nogarijr@hotmail.com

2 Doutora em Letras pela Universidade Estadual Paulista - UNESP/Campus Assis. Professor adjunto do Centro de Letras, Comunicação e Artes da Universidade Estadual do Norte do Paraná - UENP / Campus Jacarezinho. Email: nerynei@yahoo.com.br
} 


\section{Introdução}

A literatura fantástica é capaz de levar o homem a repensar a sociedade e o seu papel social, à medida que o leva a refletir sobre o significado do insólito nas narrativas. Desse modo, o insólito é aplicado na literatura não puramente para criação de um novo universo de distração e entretenimento, mas, de uma forma impactante, para levar o leitor a ponderar a respeito da realidade que o cerca.

Logo, um olhar diferenciado para essa modalidade artística é necessário, pois, além da reflexão, é capaz de levar o ser humano a desenvolver seu senso crítico e, assim, intervir em seu meio social, cumprindo seu papel humanizador, como explanou Candido (2002).

Entre os anos de 1945 a 1975, terceira geração do Modernismo, o regionalismo na literatura brasileira ganhou uma nova dimensão pela recriação dos costumes e da fala sertaneja, por meio da obra de João Guimarães Rosa, a qual adentrava intensamente na vida dos nordestinos brasileiros. Na literatura de Rosa, o fantástico era um dos elementos que se manifestava e que, seguramente, contribuiu para o sucesso do escritor.

Tendo em vista a importância do fantástico na literatura, propomos, neste trabalho, a análise do conto “Um moço muito branco”, de João Guimarães Rosa (1972), renomado escritor da literatura brasileira. Nosso intuito é investigar como o insólito se articula nesse conto; a partir dessa detecção, pretendemos buscar possíveis significados para o sobrenatural empregado na narrativa.

\section{A literatura e o fantástico: correlações e perspectivas}

Como se sabe, a arte literária é essencial a toda humanidade, pois essa, além de representar o homem e o meio em que vive, seja em tempos passados ou no presente, possui, ainda, uma função formadora. Nesse contexto:

\footnotetext{
A literatura pode formar, mas não segundo a pedagogia oficial, que costuma vê-la ideologicamente como um veículo da tríade famosa - o Verdadeiro, o Bom, o Belo, definidos conforme os interesses dos grupos dominantes, para reforço da sua concepção de vida. Longe de ser um apêndice da instrução moral e cívica (esta apoteose matreira do óbvio, novamente em grande voga), ela age com o impacto indiscriminado da própria vida e educa como ela - com altos e baixos, luzes e sombras. (CANDIDO, 2002, p. 83)
} 
Entende-se, assim, que não compete à literatura representar um mundo livre de subversões humanas, tais como desigualdades sociais, marginalismo e discriminação, mas cabe a essa conceber a vida como de fato é, com seus conflitos e soluções. Desse modo, constata-se que à arte literária cabe a função humanizadora: "Ela não corrompe nem edifica, portanto; mas, trazendo livremente em si o que chamamos o bem e o que chamamos o mal, humaniza em sentido profundo, porque faz viver” (CANDIDO, 2002, p. 85).

Em seus estudos psicanalíticos, Freud expõe a função da fantasia na humanidade, o que amplia e aprofunda as reflexões de Candido. Freud (2006) afirma que o aparelho psíquico é regido pelo princípio do prazer, que se refere a um mundo interno de cada sujeito, carregado de desejos e pulsões em busca de satisfação, e pelo princípio da realidade, que implica na conscientização do indivíduo de que não pode viver puramente em função dos seus desejos, fazendo-o habituar-se às exigências do mundo aparente.

Jacqueline Held, ao discutir o caráter paradoxal do fantástico na imbricação do insólito com o real, traz à tona pressupostos que, a nosso ver, coadunam com a tese freudiana sobre a importância do imaginário, no âmbito psíquico do ser humano, enquanto aquele que aglutina os princípios do prazer e da realidade. Nas palavras da estudiosa francesa:

O irreal do fantástico seria mesmo um irreal? O fantástico nos tocaria, a obra fantástica encontraria leitores, se não reunissem aspirações, necessidades, experiências que também trazemos em nós, em graus diversos, talvez obscuros e semi-ignorados, mas, no entanto, bem reais? (HELD, 1980, p. 25)

Por conseguinte, frente à realidade frustrante, a fantasia aparece como via de escape fundamental e indispensável aos seres humanos. Freud (2006) defende que "as forças motivadoras das fantasias são os desejos insatisfeitos, e toda fantasia é a realização de um desejo, uma correção da realidade insatisfatória” (FREUD, 2006, p. 137). O valor da fantasia na existência humana, todavia, não se restringe ao escapismo, antes atinge funções fulcrais, desencadeadoras de múltiplos efeitos e mudanças diversas no leitor. A respeito dessa temática, Held problematiza:

Expressão e prolongamento do desejo humano, resposta a esse desejo, o conto fantástico apresenta, incontestavelmente, um lado compensatório. É válvula de segurança. Quando o homem sofre muito, ele se aliena, sonha. Seríamos então tentados a ver apenas um aspecto possível do conto: essa satisfação simbólica dada a nossos desejos impediria o homem de agir, de procurar mais longe, de lutar, de inventar o futuro. [...] Por muito sonhar, desejamos tanto que inventamos. O desejo, não nos esqueçamos, é também fator de progresso. [...] O homem inventa, cria, 
descobre, precisamente porque está insatisfeito e porque sonha. [...] Sonho, motor constante do real. (1980, p. 168-169)

Dessa maneira, verifica-se a relevância da arte literária para a humanidade, à medida que essa incorpora a ficção e a fantasia em sua estrutura composicional, a qual, indiscutivelmente, opera na formação do homem. Em qualquer ser humano, inicialmente na fase pueril, a fantasia, a sensibilidade e a inteligência não são capacidades que podem facilmente progredir quando se dissociam. Pelo contrário, para desenvolver-se de maneira equilibrada, a criança necessita do imaginário, no qual:

\footnotetext{
O fantástico parece constituir uma dessas formas na medida mesma em que estimula a criança, a incita, pela própria distância que cria, a uma interrogação, a um questionamento. Esse tipo de fantástico ocupa, no crescimento da criança, lugar capital. Tem papel decisivo a desempenhar. Assim como algumas brincadeiras adulto-criança, baseadas precisamente no humor: papel de pseudo-magia proposta em tom falsamente sério, que, logo, provoca a criança, a convida a contestar, a procurar e a encontrar onde se esconde a fraude. (HELD, 1980, p. 175)
}

Pensando nas questões levantadas até aqui, propomos, neste trabalho, destacar uma das modalidades dos gêneros literários que se refere, especificamente, ao que é criado pela imaginação, o sobrenatural, o qual certamente reúne, em sua configuração, atributos mencionados por Candido e Freud, e que, como qualquer outra arte, possui seus significados implícitos, ou seja, trata-se da literatura do insólito/fantástico.

De acordo com Rodrigues (1988), o termo fantástico (proveniente do latim phantasticu, por sua vez do grego phantastikós, ambos oriundos de phantasia) alude ao que é criado pela imaginação, o não existente na realidade empírica, o imaginário, o fabuloso. Logo, aplica-se "a um fenômeno de caráter artístico, como é a literatura, cujo universo é sempre ficcional por excelência, por mais que se queira aproximá-la do real” (RODRIGUES, 1988, p. 09).

David Roas (2014), importante teórico espanhol da literatura fantástica, caracteriza essa modalidade literária como fenômeno de expressão humana e artística contemporânea, pós-moderna e global. A maior parte dos críticos literários considera o sobrenatural como uma condição indispensável para que se produza o efeito do fantástico, o que não significa que todas as obras que compreendam o sobrenatural devem ser consideradas fantásticas. No 
entanto, a literatura fantástica é a única modalidade literária a qual não pode funcionar sem o aspecto sobrenatural. Para Roas,

E o sobrenatural é aquilo que transgride as leis que organizam o mundo real, aquilo que não é explicável, que não existe, de acordo com essas mesmas leis. Assim, para que a história narrada seja considerada fantástica, deve-se criar um espaço similar ao que o leitor habita, um espaço que se verá assaltado pelo fenômeno que transtornará sua estabilidade. É por isso que o sobrenatural vai supor sempre uma ameaça à nossa realidade, que até esse momento acreditávamos governada por leis rigorosamente imutáveis. (2014, p. 31)

Desse modo, entende-se que a narrativa do fantástico insere o leitor diante do sobrenatural, porém não como evasão, mas para questioná-lo e fazê-lo perder a segurança diante da realidade que o cerca. Nesse contexto, Cortázar (1993) alega que o fantástico "reside na sua ressonância de pulsação, de palpitar surpreendente de um coração alheio ao nosso, de uma ordem que nos pode usar a qualquer momento para um dos seus mosaicos, arrancando-nos da rotina para nos pôr um lápis ou um cinzel na mão” (1993, p. 179).

Recorrendo aos estudos de Lovecraft sobre o gênero, toda a narrativa fantástica:

[...] deve ser realista e ambiental, limitando seu desvio da natureza ao canal sobrenatural escolhido, e lembrando que o cenário, o tom e os acontecimentos são mais importantes na hora de comunicar o que se pretende do que os personagens ou a própria ação. O quid de qualquer narrativa que pretende ser aterrorizante é simplesmente a violação ou superação de uma lei cósmica imutável - um escape imaginativo da tediosa realidade -, pois os "heróis” lógicos são os fenômenos, e não as pessoas. (LOVECRAFT apud ROAS, 2014, p. 52)

Para lidar com a ficção, seja em uma narrativa fantástica ou não, faz-se necessária a aceitação implícita de um acordo ficcional, ou seja, estar ciente “de que o que está sendo narrado é uma história imaginária, mas nem por isso deve-se pensar que o escritor está contando mentiras. [...] Aceitamos o acordo ficcional e fingimos que o que é narrado de fato aconteceu” (ECO, 1994, p. 81).

Por assim ser, a urdidura do gênero fantástico, a verossimilhança para com o sobrenatural, ou seja, a veracidade da trama, composta pelos traços mais perfeitos da realidade, mesmo sendo ficcional, deve ser capaz de levar o leitor a questionar o real. Para Roas (2014), na narrativa fantástica o estabelecimento de um pacto ficcional é imprescindível e, além disso, deve-se considerar a percepção do real: “depois de aceitar (pactuar) que 
estamos diante de um texto fantástico, ele deve ser o mais verossímil possível para alcançar seu correto efeito sobre o leitor” (p. 51).

Nesse sentido, H. P. Lovecraft (1987) argumenta:

\begin{abstract}
A atmosfera é o mais importante, pois o critério definitivo de autenticidade [do fantástico] não é a estrutura da intriga a não ser a criação de uma impressão específica. [...]. Por tal razão, devemos julgar o conto fantástico nem tanto pelas intenções do autor e os mecanismos da intriga, a não ser em função da intensidade emocional que provoca [...]. Um conto é fantástico, simplesmente se o leitor experimenta em forma profunda um sentimento de temor e terror, a presença de mundos e de potências insólitas. (LOVECRAFT, 1987, p. 16)
\end{abstract}

Isso ocorre, pois, nas narrativas de cunho fantástico, de maneira estratégica, ao propor uma história, os seus produtores, na verdade, têm a intenção de contar outra, a qual, evidentemente, deve ser interpretada pelo leitor, conforme Ceserani: “A presença de elementos de paródia e de discussão metanarrativa sobre os modos e sobre os códigos da narração parece uma indicação e uma sugestão da ambiguidade de toda a operação estratégica: a literatura fantástica finge contar uma história para poder contar outra”. (2006, p. 102).

Por conseguinte, cabe ao leitor interagir com a narrativa, a fim de verificar e elaborar prováveis leituras do que, na ficção, o fantástico, imbricado na história, almeja sugerir. Isso ocorre porque o fantástico exige a presença de conflitos que devem ser analisados tanto no interior do texto como também no universo extratextual. Nesse sentido, Jackson afirma que o fantástico recombina e inverte o real, porém não foge dele, estabelecendo com ele, ao invés disso, uma “relação simbiótica ou parasitária” (1981, p.20).

Consequentemente, a narrativa fantástica está formada em uma realidade cotidiana que ela constrói com técnicas realistas e, ao mesmo tempo, a destrói, implantando nela outra realidade, incompreensível à primeira. De modo a acrescentar, Roas (2014) comenta:

\footnotetext{
Essas técnicas coincidem claramente com as fórmulas utilizadas em todo texto realista para dar verossimilhança à história narrada, para afirmar a referencialidade do texto: recorrer a um narrador extradiegético-homodiegético, ambientar a história em lugares reais, descrever minuciosamente objetos, personagens e espaços, inserir alusões à realidade pragmática, etc. (2014, p. 54)
}

Pode-se dizer, portanto, que a narrativa fantástica busca a reflexão sobre a realidade e seus limites, e a inquirição a respeito da validade das ferramentas, que se constroem para entendê-la e representá-la. Segundo Casares: "Na borda das coisas que não compreendemos 
plenamente, inventamos contos fantásticos para aventar hipóteses ou para compartilhar com outros as vertigens da nossa perplexidade” (apud ROAS, 2014, p. 89).

Logo, no que diz respeito à literatura fantástica, pode-se concluir que seu valor é indireto, pois age implicitamente e em longo prazo, nos seus leitores. Held (1980) acredita que o livro fantástico provoca no leitor a desconfiança ao mesmo tempo em que: "ensina a ver, a escutar, a pensar e a viver por si mesmo [...]. Literariamente, ele des-regula. Desnormaliza. E a sociedade prefere sempre que a tranquilize e confirme sua consciência pondolhe, dentro dos olhos, a imagem estatisticamente dominante” (1980, p. 234).

\section{A configuração do insólito em "Um moço muito branco", de Guimarães Rosa}

O conto "Um moço muito branco", de Guimarães Rosa (1972), é uma das narrativas que integra a obra Primeiras estórias, cuja primeira edição foi publicada no ano de 1962. Neste conto, é narrada a história de um jovem que surge no território de Serro Frio, Estado de Minas Gerais, após um evento climático infrequente, em novembro de 1872:

\footnotetext{
NA NOITE de 11 de novembro de 1872, na comarca do Serro Frio, em Minas Gerais, deram-se fatos de pavoroso suceder, referidos nas folhas da época e exagerados nas Efemérides.

Dito que um fenômeno luminoso se projetou no espaço, seguido de estrondos, e a terra se abalou, num terremoto que sacudiu os altos, quebrou e entulhou casas, remexeu vales, matou gente sem conta; saiu outrossim medonho temporal, com assombrosa e jamais vista inundação, subindo as águas do rio e córregos a sessenta palmos de plana. (ROSA, 1972. p. 99)
}

No trecho acima, verifica-se, logo no início, uma das facetas da narrativa fantástica, a qual o americano Howard Phillips Lovecraft (1890-1937) descreve como o horror, o que certamente é responsável pela reação de medo nas personagens e que, de uma maneira peculiar, reflete no leitor. Nesse caso, o medo é resultado do fenômeno desconhecido que causou uma variedade de estragos e mortes na pequena cidade de Serro Frio do estado de Minas Gerais. Logo, Lovecraft expõe que “a emoção mais forte e mais antiga do homem é o medo, e a espécie mais forte e mais antiga do medo é o medo do desconhecido” (1987, p. 01).

Após a catástrofe, no pátio da fazenda de Hilário Cordeiro, homem cordial, temente a Deus e bom, que inclusive perdera parentes por conta do fenômeno ocorrido, surgiu um moço de distintas formas, faminto, em lástimas condições, com vestes sobrecomuns, nunca visto antes naquela região: 
Tão branco; mas tão branquicelo, senão que de um branco leve, semidourado de luz: figurando ter por dentro da pele uma segunda claridade. Sobremodo se assemelhava a êsses estrangeiros que a gente não depara nem nunca viu; fazia para si outra raça. (ROSA, 1972, p. 99-100)

A partir desse momento, o leitor é levado a refletir sobre a origem desse rapaz. Sua aparição sem explicação prévia e sua aparência distinta leva-nos, por um instante, a crer que o rapaz não é humano, mas um ser que surgiu em nosso mundo por consequência do fenômeno incomum, que causou uma série de desastres. No entanto, ao mesmo tempo em que o narrador sugere o sobrenatural, o mesmo profere uma explicação racional, comparando o moço a estrangeiros, os quais possuem a pele muito branca.

Nesse sentido, Todorov (1975) expõe que existe uma primeira condição do fantástico literário, a hesitação. Para o teórico, no gênero fantástico, haverá sempre duas soluções para o entendimento do insólito na literatura:

\begin{abstract}
Somos assim transportados ao âmago do fantástico. Num mundo que é exatamente o nosso, aquele que conhecemos, sem diabos, sílfides nem vampiros, produz-se um acontecimento que não pode ser explicado pelas leis deste mundo familiar. Aquele que o percebe deve optar por uma das duas soluções possíveis; ou se trata de uma ilusão dos sentidos, de um produto da imaginação e nesse caso as leis do mundo continuam a ser o que são; ou então o acontecimento realmente ocorreu, é parte integrante da realidade, mas nesse caso esta realidade é regida por leis desconhecidas para nós. (TODOROV, 1975, p. 30)
\end{abstract}

Com base nos estudos de Todorov, pode-se constatar que estamos diante de uma narrativa fantástica, por conta da hesitação, a qual Todorov defende como condição do fantástico, que se manifesta no conto de Guimarães Rosa pela incerteza da origem do moço muito branco.

Ampliando as considerações de Todorov, Held (1980) expõe que o fantástico provoca no leitor a desconfiança e, além disso, "ensina a ver, a escutar, a pensar e a viver por si mesmo, [...]”. (p.234). Assim sendo, à medida que o leitor mergulha na narrativa de "Um moço muito branco”, o mesmo vai tecendo suas considerações sobre a urdidura do insólito na obra e torna-se, portanto, vítima da incerteza de haver uma explicação racional para as situações engendradas, a qual se confirma ou não no desfecho da narrativa, ou ainda, essa pode não oferecer subsídios para que o leitor tire suas conclusões.

Após o aparecimento do rapaz na fazenda, Hilário Cordeiro decide acolhê-lo, oferecelhe roupas, moradia e alimentação, uma vez que o moço havia perdido completamente sua 
memória, além de sua fala, sendo capaz apenas de entender poucos gestos, o que certamente levaria o rapaz a vagar sem rumo e, até mesmo, chegar à morte.

O novo morador da cidade, então, passou a conviver com os moradores da fazenda, com os vizinhos que ali iam visitá-lo e a frequentar lugares públicos. Dentre esses lugares, em companhia de Hilário Cordeiro, o rapaz era conduzido à igreja para frequentar as missas. O jovem, sempre calado, não demonstrava gestos de aprovação ou desaprovação para situação vivida alguma, mas estava sempre a sorrir com o rosto e com os olhos perante qualquer ocorrência. Tal fato transporta o leitor novamente à hesitação apresentada por Todorov (1975), ou a desconfiança postulada por Held (1980), levando-o a questionar quem de fato é este rapaz e de onde o mesmo viera, o que afinal é um dos papéis do fantástico na literatura, levar o leitor à reflexão.

No decorrer do conto, ao sair da igreja, o protagonista se depara com a personagem Nicolau, o cego pedinte e, ao encará-lo, vai a seu encontro e entrega-lhe uma semente que retirou do bolso:

\begin{abstract}
O cego, apalpando a dádiva na mão, em guisa de cogitar em que estúrdia casta de moeda ela consistisse, e se dissertando logo que nenhuma, a levou prestes à boca; ao que, seu menino guia o advertiu: que não seria artigo de se comer, mas espécie de caroço de árvore. Então o cego guardou, com irados ciúmes e por diversos meses, aquela semente, que só foi plantada após o remate dos fatos aqui ainda por narrar: e deu um azulado pé de flor, da mais rara e inesperada: com entre aspecto de serem várias flores numa única, entremeadas de maneira impossível, num primor confuso, e, as cores, ninguém a respeito delas concordou, por desconhecidas no século; definhada, com pouco, e secada, sem produzir outras sementes nem mudas, e nem os insetos a sabiam procurar. (ROSA, 1972, p. 101-102)
\end{abstract}

Com base no fragmento acima, verifica-se a manifestação efetiva do insólito na obra de Guimarães Rosa. O moço muito branco entrega ao cego uma semente que, após determinado tempo, gera uma planta nunca vista antes, que leva o leitor a crer que o moço não pertence àquele lugar. A partir do momento que um acontecimento não pode ser explicado pelas leis naturais, neste caso, o surgimento repentino de uma semente que gera uma nova espécie de planta, Todorov (1975) sugere a existência do sobrenatural, classificando essa modalidade fantástica de fantástico-maravilhoso:

Encontramo-nos no campo do fantástico-maravilhoso, ou, dito de outra maneira, dentro da classe de relatos que se apresentam como fantásticos e que terminam com a aceitação do sobrenatural. Estes relatos são os que mais se aproximam do fantástico puro, pois este, pelo fato mesmo de ficar inexplicado, não racionalizado, sugere-nos, em efeito, a existência do sobrenatural. O limite entre ambos será, pois, 
incerto, entretanto, a presença ou ausência de certos detalhes permitirá sempre tomar uma decisão. (TODOROV, 1975, p. 29)

Em contrapartida à teoria de Todorov acerca do fantástico-maravilhoso, Fernández (2011) apresenta-nos o realismo-maravilhoso, que se refere à mutação do comum e do habitual em uma vivência que abrange experiências sobrenaturais ou fantásticas:

La transformación de lo cotidiano en inverosímil - con frecuencia por medio de su exageración - y la utilización eficaz por medio de un narrador imperturbable de sucesos increíbles. Relacionada con el relato oral y con la imaginación infantil, esa manera de narrar insiste en ser el testimonio de una mentalidad no coartada por el racionalismo. De esa mentalidad, en resumidas cuentas, fue manifestación el realismo mágico, que parecía dar la razón a quienes pensaban que las culturas más creativas (literariamente) eran aquellas que se encontraban más próximas a los orígenes, las que aún conservaban vivo su caudal de mitos y de leyendas derivadas de los mitos. (FERNÁNDEZ apud ROAS, 2011, p. 291-292)

Diante disso, evidencia-se que, no realismo-maravilhoso, os acontecimentos diversificados nas obras literárias são reais, todavia, os mesmos trazem uma conotação implícita, pois não apresentam uma explicação racional por se tratar de um fato muito improvável de ocorrer na realidade empírica, assim como no fantástico-maravilhoso descrito por Todorov.

Confirmando a presença do sobrenatural no conto, o moço muito branco realiza outra façanha que nos leva a questionar a origem e identidade do rapaz. Em uma visita ao sítio de Duarte Dias, ele se depara com Viviana, jovem que vivia seus dias com tristeza e angústias, e, ao tocá-la, a moça troca sua tristeza por felicidade:

Do que adveio, justo, o caso da môça Viviana, sempre mal contado. O que foi quando ele já apareceu, acompanhado do preto José Kakende, e deu com a moça, mui bonita, mas que não se divertia ao igual das outras: e ele se chegou muito a ela, gentil e espantoso, lhe pôs a palma da mão no seio, delicadamente. Ora, sendo assim a môça Viviana a mais formosa, tinha-se para admirar que a beleza do feitio lhe não servisse para transformar, no interior, a própria e vagarosa tristeza. Mas, Duarte Dias, o pai, e que a isso assistia, prorrompeu em pleiteantes brados de: - "Tem que casar! Agora, tem de casar!" - com instância. Afirmava que o moço era homem, e um, e ainda mancebo, e lhe infamara a filha, devendo-lhe de a tomar por consorte e arcar com o estado de casado. O môço ouvia, de boa concórdia, e nem por isso. Mas a grita de Duarte Dias só teve termo, quando o padre Bayão, e outros dos mais velhos, lhe rejeitaram tão descabidas fúrias e insensatez. Também a moça Viviana, com radiosos sorrisos, o serenava. Ela, que, a partir dessa hora, despertou em si um enfim de alegria, para todo o restante de sua vida, donde um dom. Apenas que, Duarte Dias - o que não se entende - ia produzir ainda outros lances de estupefação, eis-aqui. (ROSA, 1972, p. 103) 
O desfecho do conto se dá com a partida do moço, a qual, devido aos aspectos insólitos demonstrados, confirma a hipótese do moço não pertencer ao meio dos homens. O moço, com a ajuda de José Kakende, cria asas e parte de Sêrro Azul:

\begin{abstract}
Mas, por conta, no dia da venerada Santa Brígida, de voz comum de novo dele se soube: o moço, plácido. Disse-se, que safra, na véspera, de paragem, pelos altos, num de seus desapareceres; era um tempo de trovoadas secas. José Kakende contava somente que o ajudara a acender, de secreto, com formato, nove fogueiras; e, mais, o Kakende soubesse apenas repetir aquelas suas velhas e divagadas visões - de nuvem, chamas, ruídos, redondos, rodas, geringonça e entes. Com a primeira luz do sol, o moço se fora, tidas asas. (ROSA, 1972, p. 104)
\end{abstract}

Embora identificada a configuração do insólito no conto de Guimarães Rosa, é indispensável o questionamento de seu significado na narrativa, pois como expõe Ceserani (2006), de maneira estratégica, a narrativa fantástica, ao propor uma história, na verdade tem a intenção de contar outra. Desse modo, cabe ao leitor interagir com a narrativa, a fim de verificar e elaborar prováveis leituras do que, na ficção, o fantástico, imbricado na história, anseia sugerir.

O sobrenatural, correlacionado à realidade empírica, pode ser compreendido no conto como uma possível intenção do autor de revelar que a vida não deve ser encarada e compreendida apenas pela razão e pela lógica, porém, deve-se considerar a imaginação e os devaneios, os quais, certamente, contribuem para o desenvolvimento humano cognitivo e psíquico, pois podem representar subsídios ao homem para que esse seja capaz de lidar melhor com suas próprias pulsões diante do mundo real.

Por fim, apreciando o conto abordado nesta análise, é perceptível certo tom de religiosidade, uma vez que a personagem do moço muito branco é descrita como alguém com muita luz e cordialidade cuja partida de Sêrro Azul ocorre "Com a primeira luz do sol”, por meio da alusão a um ser alado “[...] o moço se fora, tidas asas” (ROSA, 1972, p. 104). Além disso, o rapaz tinha o dom de, inexplicavelmente, imprimir felicidade aos oprimidos e marginalizados, como é o caso do cego pedinte e da solteirona amargurada, supramencionados. Nesse sentido, uma das possíveis leituras, descortinadas por esta análise, é de que o jovem veio dos céus e para lá retorna, ao final de sua jornada na terra. Provavelmente, trata-se de um anjo de luz do bem, cuja missão foi trazer "luminosidade” aos problemas humanos, conforme acepções cristãs, predominantes na sociedade e cultura brasileiras. 
É aceitável considerar que, em meio ao mundo cético como o contemporâneo, no qual as pessoas estão se tornando cada vez mais individualistas, sem se preocuparem com a figura do próximo e sem preparo para eventuais desafios ou dificuldades, a fé e a esperança são imprescindíveis à vida e tais estados da alma, imprescindíveis à vivência humana, não se explicam pela razão, antes, pelo sobrenatural, vigente além das barreiras do verismo imediato, ou seja, transcende as personificações e circunstâncias da realidade aparente, ao mesmo tempo em que dela faz alusivas referências, numa relação simbiótica, afim ao fantástico literário, conforme Jackson (1981).

\section{Considerações finais}

Com base na leitura e análise do conto "Um moço muito branco”, de Guimarães Rosa, é possível entender a importância do sobrenatural empregado na narrativa. O fantástico não é empregado simplesmente para a construção de uma história ficcional sem significado, mas o mesmo é construído para chamar a atenção do leitor para a realidade que o cerca, para que seja capaz de, por meio de sua nova visão, introduzida pela literatura, ser capaz de transformar a sociedade e o seu meio.

Na obra de Rosa, o leitor é levado a pensar sobre a existência de uma nova realidade, sobre a qual não poderia cogitar sem a aplicação do fantástico na literatura. Tal modalidade leva a humanidade a enxergar novas facetas do que pode ser considerado real, contribuindo, desse modo, para o desenvolvimento da sociedade.

Conforme a análise efetuada, é possível apreender que o fantástico-maravilhoso, aqui descortinado, revela procedimentos paradoxais quanto à estrutura formal e temática do conto rosiano. Isso porque, embora se instaure e seja mantido no texto por meio da personagem e das ações insólitas, traz, nas entrelinhas, questões sociais e psíquicas, inerentes à vivência humana, plausível no mundo real.

\section{Referências}

CANDIDO, A. A Literatura e a formação do homem. Textos de Intervenção. São Paulo: Duas Cidades; Ed. 34, 2002. 
CESERANI, R. O fantástico. Tradução de Nilton Cezar Tridapalli. Curitiba, Londrina: UFPR/EDUEL, 2006.

CORTÁZAR, J. Válise de Cronópio. 2. ed. São Paulo: Perspectiva, 1993.

ECO, Humberto. Seis passeios pelos bosques da fição. São Paulo: Companhia das Letras, 1994.

FREUD, S. Escritores criativos e devaneios. In: . “Grávida” de Jensen e outros trabalhos (1906-1908). Volume IX. Rio de Janeiro: Imago, 2006. p. 131-143.

HELD, J. O imaginário no poder: as crianças e a literatura fantástica. São Paulo: Summus, 1980.

JACKSON, R. Fantasy, the Literature of Subversion. New York: New Accents, 1981.

LOVECRAFT, H. P. O horror sobrenatural na literatura. Trad. de Guilherme Linke. Rio de Janeiro: Francisco Alves, 1987.

ROAS, D. A ameaça do fantástico, aproximações teóricas. São Paulo: Editora Unesp, 2013. In: Teorías de lo Fantástico. Madrid: Arco/Libros, 2011.

ROSA, João G. Um moço muito branco. In: Primeiras estórias. 46a . imp. Rio de Janeiro: Nova Fronteira, 1972.

RODRIGUES, S. C. O Fantástico. São Paulo: Ed. Ática, 1988.

TODOROV, T. Introdução à literatura fantástica. Tradução de Maria Clara Correa Castello. São Paulo: Perspectiva, 1975. 